\title{
Effects of Aromatic Ammoniums on Methyl Ammonium Lead Iodide Hybrid Perovskite Materials
}

\author{
Jianli Yang, ${ }^{1,2,3}$ Yan Yu, ${ }^{2}$ Liyang Zeng, ${ }^{2}$ Yiting Li, ${ }^{2}$ Yaoqi Pang, \\ Fuqiang Huang, ${ }^{1,2}$ and Bo-Lin Lin ${ }^{2}$ \\ ${ }^{1}$ Shanghai Institute of Ceramics, Chinese Academy of Sciences, Shanghai 200050, China \\ ${ }^{2}$ School of Physical Science and Technology, ShanghaiTech University, Shanghai 201210, China \\ ${ }^{3}$ University of Chinese Academy of Sciences, Beijing 100039, China \\ Correspondence should be addressed to Bo-Lin Lin; linbl@shanghaitech.edu.cn
}

Received 4 November 2016; Accepted 8 December 2016; Published 12 January 2017

Academic Editor: Giovanni Bongiovanni

Copyright (C) 2017 Jianli Yang et al. This is an open access article distributed under the Creative Commons Attribution License, which permits unrestricted use, distribution, and reproduction in any medium, provided the original work is properly cited.

\begin{abstract}
The introduction of bulky ammoniums into methyl ammonium lead iodide hybrid perovskites $\left(\mathrm{MAPbI}_{3}\right)$ has emerged as a promising strategy to improve the properties of these materials. In the present work, we studied the effects of several aromatic ammoniums onto the structural, electronic, and optical properties of $\mathrm{MAPbI}_{3}$. Although powder XRD data suggest that the bulky cations are not involved in the bulk phase of the $\mathrm{MAPbI}_{3}$, a surprisingly large effect of the bulky cations onto the photoluminescence properties was observed.
\end{abstract}

\section{Introduction}

Organic-inorganic lead halide perovskite materials have been attracting increasing attention due to the soaring solar-toelectric power conversion efficiency [1-4]. Their exceptional properties, including long diffusion length, high carrier mobility, weak exciton binding energy [5], widely tunable bandgap, and high extinction efficiency [6], render them ideal and outstanding materials for applications in light-emitting diodes [7, 8], field effect transistors [9], and water photolysis besides solar cells [10].

Among the family of organic-inorganic hybrid perovskite, three-dimensional perovskite, in the formula of $\mathrm{ABX}_{3}$, has emerged in the area of photovoltaic devices. A typical 3D perovskite is comprised of a three-dimensional network of corner-sharing BX6 octahedrons while $A$ cations are filling the resulting 12 -fold coordinated holes among the periodical octahedrons. During the past few years, many efforts have been made to vary the $B$ cations [11-13] and the $X$ anions [14-17]. In order to obtain a 3D perovskite structure, the sizes of the ions should satisfy a certain requirement named as tolerance factor, which can be determined by the semiempirical formula:

$$
t=\frac{\left(r_{A}+r_{X}\right)}{\sqrt{2}\left(r_{B}+r_{X}\right)},
$$

where $r_{A}, r_{B}$, and $r_{X}$ refer to the radii of $A, B$, and $X$ ions, respectively. Generally speaking, $0.78<t<1.05$ should be satisfied for perfectly packed perovskite [18], resulting in the fact that, for given $B$ and $X$ ions, the choice of $A$ cations is limited. Hence, the tuning of $A$ cations is still relatively unexplored to date compared with that for $B$ and $X$.

Recent work indicates that mixed-cation lead halide perovskites, in which small methyl ammonium (MA) cation and another bulkier organic ammonium cation are used, can lead to various intriguing properties. Mei et al. [3]. managed to obtain perovskite with low defect concentration as well as better device performance by mixing MA and 5-aminovaleric acid (5-AVA) cations presumably due to the ability of the bifunctional 5-AVA to induce a better film growth at the meso- $\mathrm{TiO}_{2} /$ perovskite interface. Yao et al. [19] fabricated 

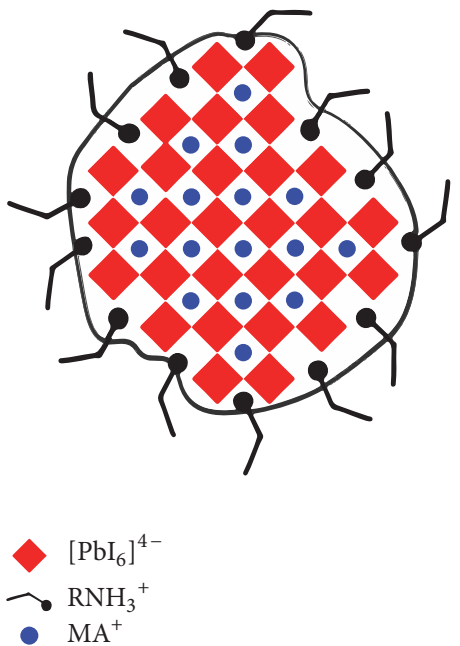

FIGURE 1: A schematic picture of a mixed-cation perovskite.<smiles>[NH3+]c1ccccc1</smiles>

(a)

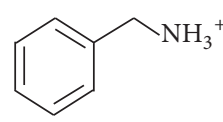

(b)

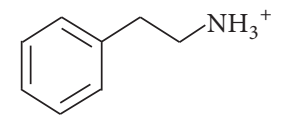

(c)
FIgURE 2: Structures of ammoniums: (a) anilinium (A), (b) benzyl ammonium (BA), and (c) phenethyl ammonium (PEA).

perovskite solar cells with smooth, ultrahigh surface coverage films through mixing polyethylenimine (PEI) and MA cations. Given the size limitation of the coordinated holes, these bulky cations usually replace the MA cations in the surface and anchored into the inorganic framework by an ammonium group (Figure 1), similar to the structure described in the work by Yang and coworkers [20].

This promising recent progress highlights the importance of tuning the organic cation of perovskites for the improvement of photoelectronic devices made of perovskite materials. However, due to the lack of systematic studies for the effects of the cations, several important fundamental questions remain unanswered. Specifically, the influence of the diverse organic cations may make onto-key properties such as the crystal structure, the band structure, and luminescence characters remain unclear.

Herein, we report our studies for mixed-cation perovskites using aromatic ammoniums with various linkers between the aromatic ring and the ammonium cation. In particular, a surprising effect of the bulky cations onto the photoluminescence (PL) properties is disclosed. Three ammoniums, including anilinium (A), benzyl ammonium (BA), and phenethyl ammonium (PEA), were probed (Figure 2).

\section{Experimental Procedures}

2.1. Synthesis of Amine Salts. The $\mathrm{CH}_{3} \mathrm{NH}_{3} \mathrm{I}$ was synthesized by reacting $25 \mathrm{~mL}$ of $\mathrm{CH}_{3} \mathrm{NH}_{2}$ and $10 \mathrm{~mL}$ of $\mathrm{HI}$ in a $100 \mathrm{~mL}$ round-bottom flask at $0^{\circ} \mathrm{C}$ for $2 \mathrm{~h}$ with stirring. The precipitate was collected using a rotary evaporator through carefully removing the solvents at $50^{\circ} \mathrm{C}$. The as-obtained product was redissolved at $70^{\circ} \mathrm{C}$ in ethanol and left cooling for $12 \mathrm{~h}$. The final $\mathrm{CH}_{3} \mathrm{NH}_{3} \mathrm{I}$ was collected by filtering the cooling solution and dried at $60^{\circ} \mathrm{C}$ in a vacuum oven for $24 \mathrm{~h}$. The $\mathrm{C}_{6} \mathrm{H}_{5} \mathrm{NH}_{3} \mathrm{I}, \mathrm{C}_{6} \mathrm{H}_{5} \mathrm{CH}_{2} \mathrm{NH}_{3} \mathrm{I}$, and $\mathrm{C}_{6} \mathrm{H}_{5} \mathrm{C}_{2} \mathrm{H}_{4} \mathrm{NH}_{3} \mathrm{I}$ were synthesized following the procedures of the synthesizing of $\mathrm{CH}_{3} \mathrm{NH}_{3} \mathrm{I}$.

2.2. Synthesis of Perovskite Materials. The mixed-cation materials were obtain through a mortar-and-pestle grinding method where a 1:1:2 molar ratios of MA iodide, aromatic ammonium iodide, and lead iodide were mixed and ground for 30 minutes. During the grinding processes, the powder mixture turned from yellow to dark yellow, then brown, and finally black with shining facets typically seen for perovskites. For convenience, these materials were abbreviated as AMA, BAMA, and PEAMA, respectively. For the sake of accuracy, all the experiments were conducted three times.

2.3. Characterization. X-ray powder diffraction measurements were performed on the Bruker AXS D2 Phaser using $\mathrm{Cu}-\mathrm{K} \alpha$ radiation $(\lambda=1.54050 \AA)$ with the following measurement conditions: tube voltage of $30 \mathrm{KV}$, tube current of $10 \mathrm{~mA}$, step-scan mode with a step size of $0.02^{\circ}$, and counting time of $1 \mathrm{~s}$ per step. Optical diffuse-reflectance measurements were performed on the Agilent Cary 5000. Scan electron microscope images were recorded by Carl Zeiss Supra 55 Sapphire FESEM. Photoluminescence (PL) steady measurements were performed by Horiba Fluorolog3 setup with the PL signals detected by the photomultiplier tube (PMT) detector. Photoluminescence decay measurements were performed in time correlated single photon counting (TCSPC) with $100 \mathrm{MHz}$ delta diode laser as the excitation.

\section{Results and Discussion}

The scanning electron microscopy (SEM) images (Figure 3) indicate that all three materials are essentially composed of nanoparticles with the sizes roughly on the order of tens of nanometers. In spite of the presence of 1 equivalent of the bulky cations, the powder XRD patterns (Figure 4) show broad main peaks $(2 \theta)$ close to $14.1^{\circ}, 28.5^{\circ}, 31.9^{\circ}, 40.5^{\circ}$, and $43.0^{\circ}$ for all three materials, which can be ascribed to (110), (220), (310), (224), and (314) for tetragonal $\mathrm{MAPbI}_{3}$ perovskite, respectively [21-23], indicating that the aromatic ammoniums are not involved in the bulk phase of the $\mathrm{MAPbI}_{3}$. Apart from the main phase, minor peaks corresponding to $\mathrm{PbI}_{2}$ and $\mathrm{RNH}_{3} \mathrm{I}$ are also observed. According to Scherrer formula, the average grain sizes for AMA, BAMA, and PEAMA are estimated as $16.0 \mathrm{~nm}, 13.9 \mathrm{~nm}$, and $8.1 \mathrm{~nm}$, respectively, consistent with the SEM results. These different sizes seem to suggest that the growth of the grains may be controlled by the rate of the reaction between the aromatic ammonium and $\mathrm{MAPbI}_{3}$. Since the coverage of the grain boundary by the bulky ammonium cations can stop its further growth, the bulky cations with stronger steric hindrance (A > BA > PEA), which is mainly determined by the group directly connected with the ammonium, should result in 


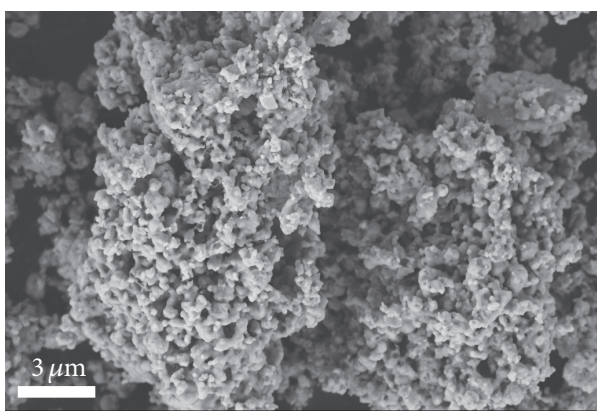

(a)

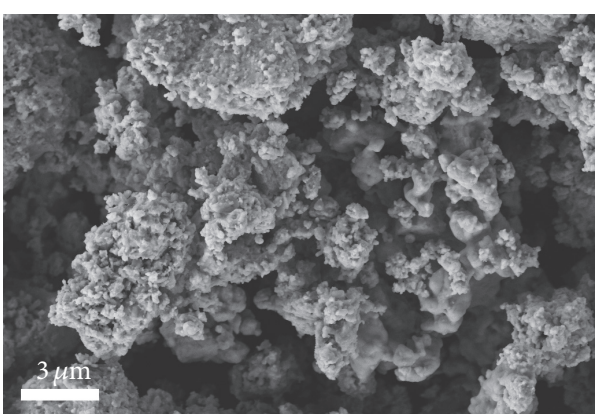

(c)

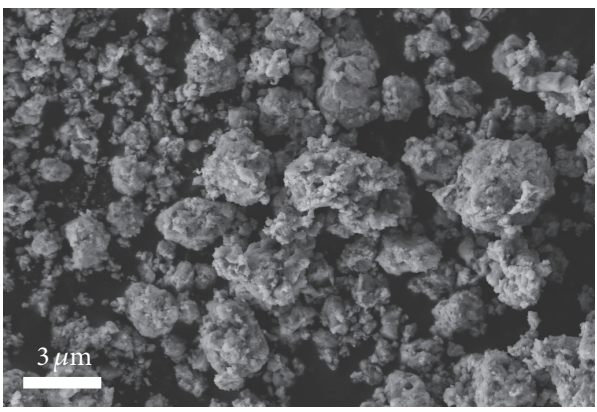

(e)

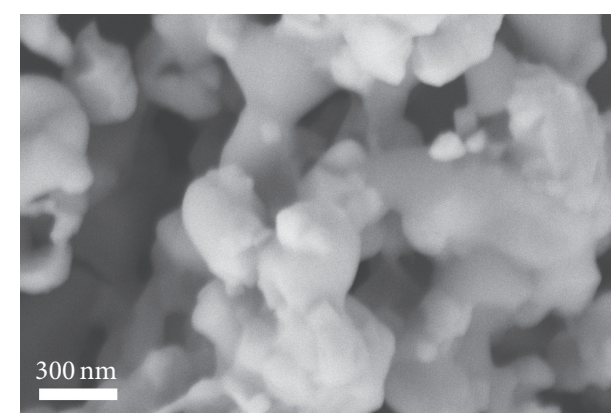

(b)

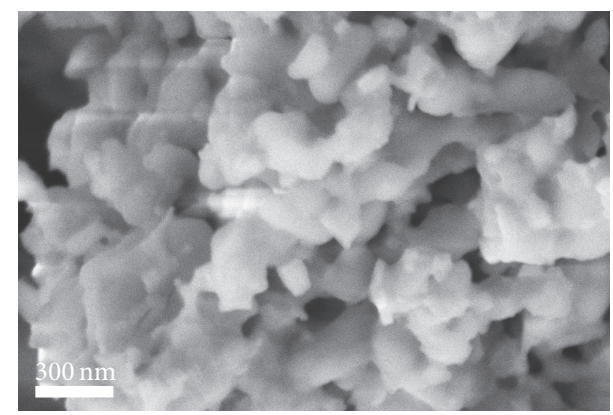

(d)

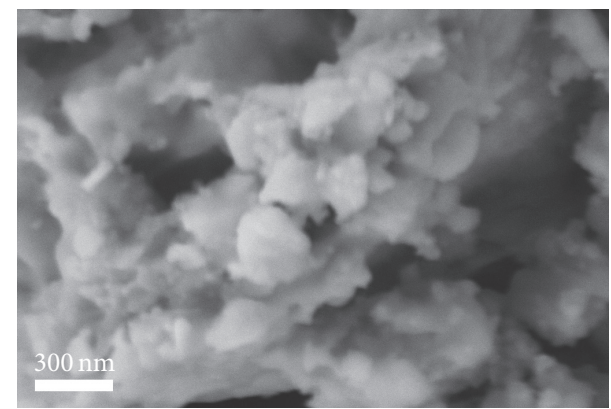

(f)

FIGURE 3: SEM images of low magnification of (a) AMA; (c) BAMA; (e) PEAMA and high magnification of (b) AMA; (d) BAMA; (f) PEAMA.

larger grain sizes due to their slower reaction rates. As such, the grain size decreases as the distance between the bulky phenyl ring and the ammonium decreases $(\mathrm{A}<\mathrm{BA}<\mathrm{PEA})$.

The bandgap of the samples can be determined from diffuse-reflectance measurements. All three materials exhibit intense optical absorption with abrupt edges similar to $3 \mathrm{D}$ $\mathrm{MAPbI}_{3}$ perovskite in the visible region (Figure 5). According to Kubelka-Munk equation, the optical absorption coefficient $(\alpha / S)$ can be calculated:

$$
F(R)=\frac{\alpha}{S}=\frac{(1-R)^{2}}{2 R}
$$

where $R$ is percentage of reflected light while $\alpha$ and $S$ are the absorption and scattering coefficients. By extrapolating the line part of the $[F(R) \cdot h v]^{2}$ versus $h v$ plot, the bandgaps of the materials are obtained (Figure S1, in Supplementary Material available online at https://doi.org/10.1155/2017/1640965). The bandgaps of the samples are $1.58 \mathrm{eV}, 1.59 \mathrm{eV}$, and $1.61 \mathrm{eV}$ for AMA, BAMA, and PEAMA, respectively. The bandgaps of these mixed-cation perovskites are all different and larger than that of $\mathrm{MAPbI}_{3}(c a .1 .51 \sim 1.52 \mathrm{eV})[21,23,24]$, indicating that organic cation has a great influence on the material's bandgap even though they are not allowed to enter the interior lattice of the $\mathrm{MAPbI}_{3}$ perovskites. Interestingly, the bandgap increases as the distance between the phenyl group and the ammonium group increases $(\mathrm{A}<\mathrm{BA}<\mathrm{PEA})$.

The steady-state photoluminescence spectra are shown in Figure 6(a). The strong PL peaks, centered at about $790 \mathrm{~nm}$, are slightly red-shifted from the optical band edge with little stokes shift, suggesting the recombination of the photoinduced electrons and holes near the band edge [25]. Surprisingly, a dramatic effect of the bulky cations on the PL intensity is observed even though they tend to appear on the grain boundaries. The PL intensity for AMA is the lowest while that for BAMA it is the highest. The large steric hindrance of anilinium distorts the structure significantly, presumably creating defect states and quenching the luminescence. Comparing BAMA and PEAMA, the lower PL intensity of the latter 


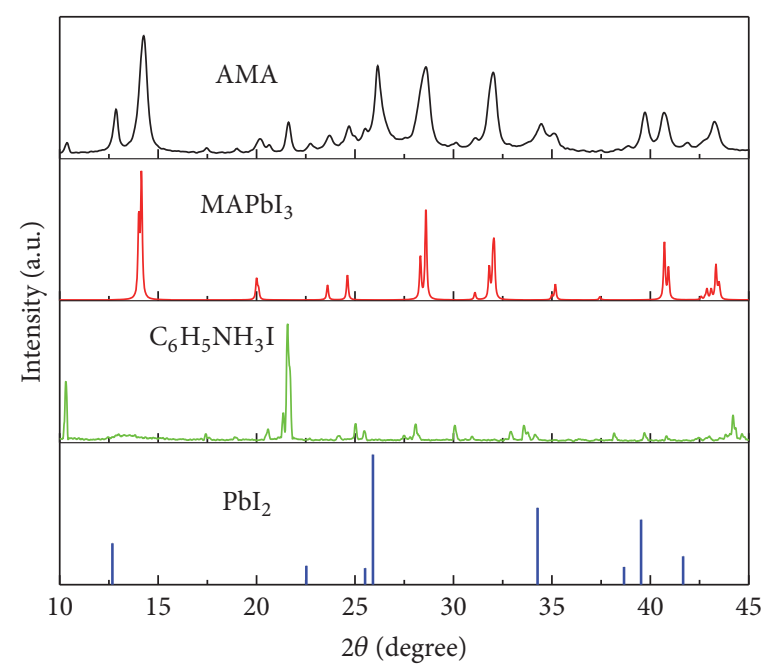

(a)

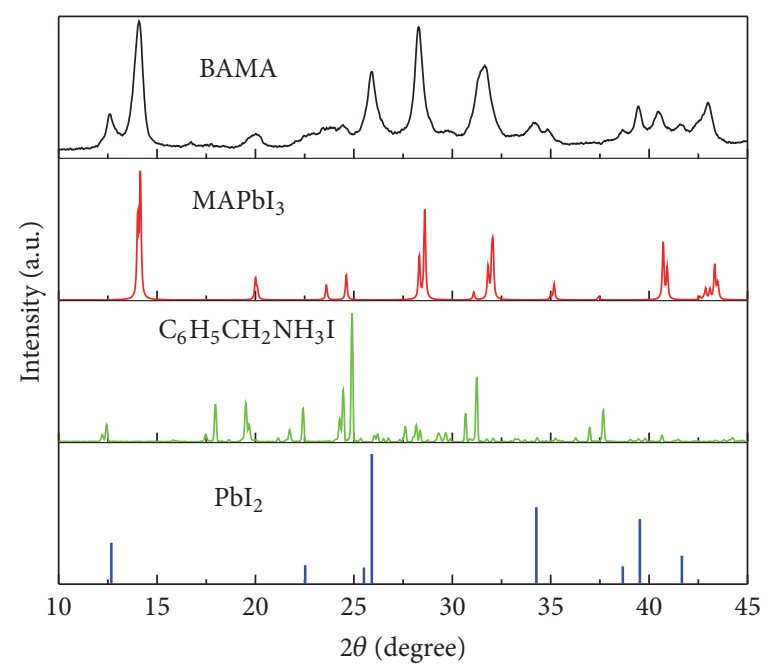

(b)

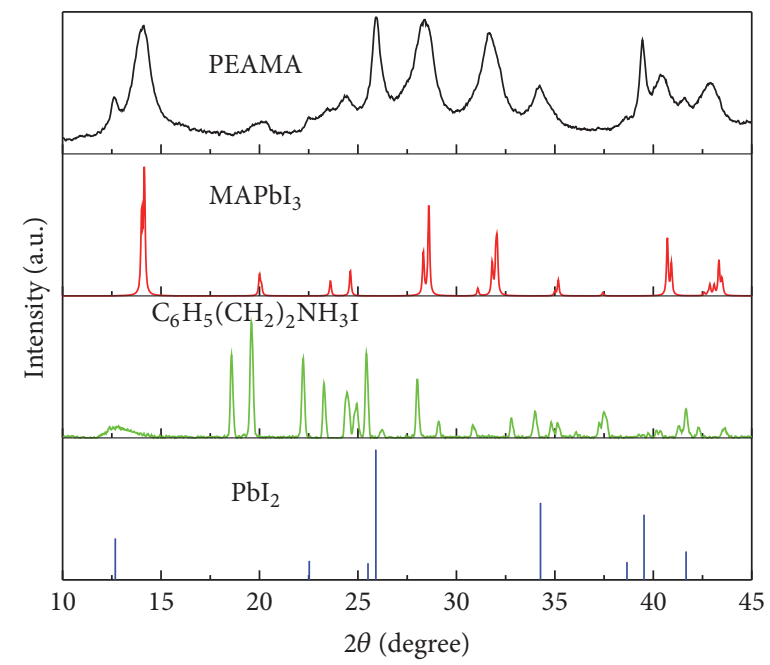

(c)

FIGURE 4: XRD patterns of (a) AMA, (b) BAMA, and (c) PEAMA samples.

might be attributed to its relatively higher degree of freedom that leads to more pathways for nonradiative decay of the excited states. Furthermore, the emission spectra are very narrow, with the full-width at half-maximum (FWHM) of all about $40 \mathrm{~nm}$ (BAMA $37.0 \mathrm{~nm}$, PEAMA $38.9 \mathrm{~nm}$, and AMA $39.1 \mathrm{~nm}$ ). Given the positive correlation between the values of FWHM and the density of defect states or shallow trapping levels [26], BAMA appears to contain the least defect states among all three materials, in accordance with its highest PL intensity.

The time-resolved PL measurements are shown in Figure 6(b). Triexponential fits were performed to quantify the carrier dynamics since biexponential function could not fit the curves well. Each of the materials shows a combination of three decay dynamics (Table 1). Pure MA perovskites typically display two-exponential decay dynamics, a longer-lifetime process for a bulk component and a shorter-lifetime one for a surface trap state component [21]. Analogously, we assign the
TABLE 1: Three-exponential decay dynamics of perovskite compounds.

\begin{tabular}{lcccccc}
\hline Sample & $\tau 1(\mathrm{~ns})$ & Ratio & $\tau 2(\mathrm{~ns})$ & Ratio & $\tau 3(\mathrm{~ns})$ & Ratio \\
\hline AMA & 9 & $43 \%$ & 32 & $39 \%$ & 2 & $18 \%$ \\
BAMA & 23 & $51 \%$ & 86 & $45 \%$ & 4 & $4 \%$ \\
PEAMA & 19 & $47 \%$ & 76 & $35 \%$ & 6 & $18 \%$ \\
\hline
\end{tabular}

longest-lifetime process of all three mixed-cation materials to the bulk component. This lifetime may reflect the competition between the radiative and nonradiative pathways inside the materials [27]. The longer the lifetime (BAMA > PEAMA > AMA), the less the nonradiative recombination sites it has, in line with the relative PL intensity (BAMA > PEAMA > AMA). The two shorted-lifetime processes might be attributed to different surface trap states corresponding to 


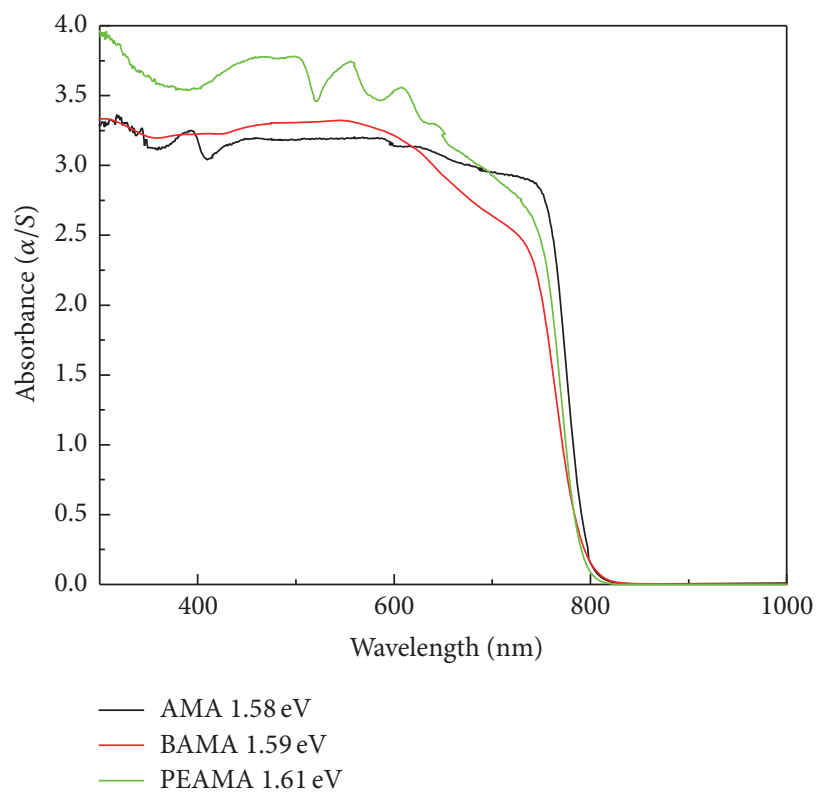

FIGURE 5: Absorbance and bandgap of perovskite samples.

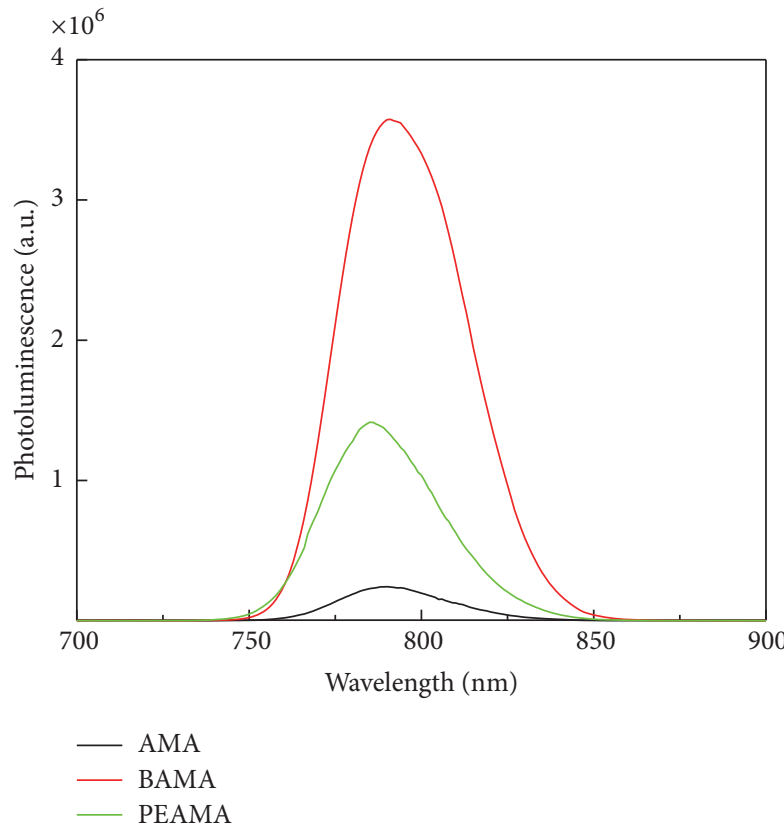

(a)

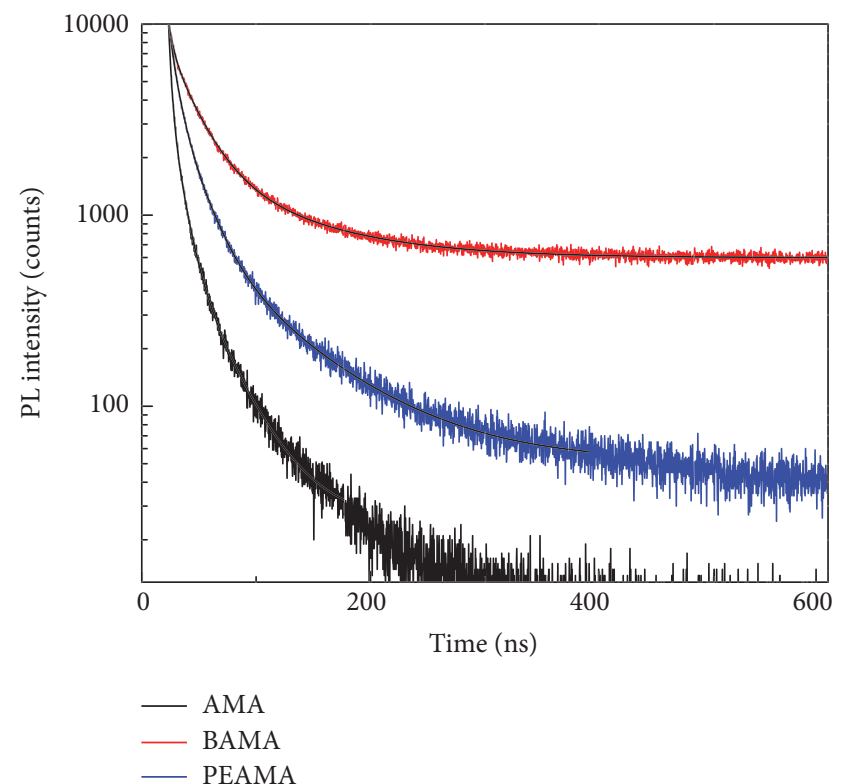

(b)

FIgURE 6: (a) Steady-state PL spectra of perovskite samples. (b) Time-resolved PL measurements showing triexponential decay.

MA and the bulky cation, respectively. The relative contribution of each lifetime was calculated and listed in Table 1.

\section{Conclusions}

In conclusion, we disclose a simple method to prepare $\mathrm{MAPbI}_{3}$ perovskites in the presence of a bulky cation. Although the probed bulky cations are too large to fit into the coordinated holes of three-dimensional perovskites and tend to stay on the grain boundaries, a remarkable effect onto the bandgaps and the PL properties is observed. These results indicated the great potential of using the mixed-cation approach to tune the properties of perovskite materials.

\section{Competing Interests}

The authors declare that there is no conflict of interests regarding the publication of this paper. 


\section{Acknowledgments}

This work is financially supported by National Science Foundation of China (NSFC U1532125).

\section{References}

[1] A. Kojima, K. Teshima, Y. Shirai, and T. Miyasaka, "Organometal halide perovskites as visible-light sensitizers for photovoltaic cells," Journal of the American Chemical Society, vol. 131, no. 17, pp. 6050-6051, 2009.

[2] H. Zhou, Q. Chen, G. Li et al., "Interface engineering of highly efficient perovskite solar cells," Science, vol. 345, no. 6196, pp. 542-546, 2014.

[3] A. Mei, X. Li, L. Liu et al., "A hole-conductor-free, fully printable mesoscopic perovskite solar cell with high stability," Science, vol. 345, no. 6194, pp. 295-298, 2014.

[4] N. J. Jeon, J. H. Noh, W. S. Yang et al., "Compositional engineering of perovskite materials for high-performance solar cells," Nature, vol. 517, no. 7535, pp. 476-480, 2015.

[5] M. Grätzel, "The light and shade of perovskite solar cells," Nature Materials, vol. 13, no. 9, pp. 838-842, 2014.

[6] C. Bi, Q. Wang, Y. Shao, Y. Yuan, Z. Xiao, and J. Huang, "Nonwetting surface-driven high-aspect-ratio crystalline grain growth for efficient hybrid perovskite solar cells," Nature Communications, vol. 6, article 7747, 2015.

[7] Z.-K. Tan, R. S. Moghaddam, M. L. Lai et al., "Bright light-emitting diodes based on organometal halide perovskite," Nature Nanotechnology, vol. 9, no. 9, pp. 687-692, 2014.

[8] H. Cho, S.-H. Jeong, M.-H. Park et al., "Overcoming the electroluminescence efficiency limitations of perovskite light-emitting diodes," Science, vol. 350, no. 6265, pp. 1222-1225, 2015.

[9] X. Y. Chin, D. Cortecchia, J. Yin, A. Bruno, and C. Soci, "Lead iodide perovskite light-emitting field-effect transistor," Nature Communications, vol. 6, article no. 7383, 2015.

[10] J. Luo, J.-H. Im, M. T. Mayer et al., "Water photolysis at $12.3 \%$ efficiency via perovskite photovoltaics and Earth-abundant catalysts," Science, vol. 345, no. 6204, pp. 1593-1596, 2014.

[11] J. Navas, A. Sánchez-Coronilla, J. J. Gallardo et al., "New insights into organic-inorganic hybrid perovskite $\mathrm{CH} 3 \mathrm{NH} 3 \mathrm{PbI} 3$ nanoparticles. An experimental and theoretical study of doping in $\mathrm{Pb} 2+$ sites with Sn2+, Sr2+, Cd2+ and Ca2+," Nanoscale, vol. 7, no. 14, pp. 6216-6229, 2015.

[12] F. Hao, C. C. Stoumpos, D. H. Cao, R. P. H. Chang, and M. G. Kanatzidis, "Lead-free solid-state organic-inorganic halide perovskite solar cells," Nature Photonics, vol. 8, no. 6, pp. 489-494, 2014.

[13] N. K. Noel, S. D. Stranks, A. Abate et al., "Lead-free organicinorganic tin halide perovskites for photovoltaic applications," Energy \& Environmental Science, vol. 7, no. 9, pp. 3061-3068, 2014.

[14] J. H. Noh, S. H. Im, J. H. Heo, T. N. Mandal, and S. I. Seok, "Chemical management for colorful, efficient, and stable inorganic-organic hybrid nanostructured solar cells," Nano Letters, vol. 13, no. 4, pp. 1764-1769, 2013.

[15] S. Nagane, U. Bansode, O. Game, S. Chhatre, and S. Ogale, " $\mathrm{CH}_{3} \mathrm{NH}_{3} \mathrm{PbI}_{(3-x)}\left(\mathrm{BF}_{4}\right)_{x}$ : molecular ion substituted hybrid perovskite," Chemical Communications, vol. 50, no. 68, pp. 97419744, 2014.

[16] Q. Chen, H. Zhou, Y. Fang et al., "The optoelectronic role of chlorine in $\mathrm{CH}_{3} \mathrm{NH}_{3} \mathrm{PbI}_{3}(\mathrm{Cl})$-based perovskite solar cells," Nature Communications, vol. 6, article 7269, 2015.
[17] J. Yan, B. Zhang, Y. Chen, A. Zhang, and X. Ke, "Improving the photoluminescence properties of perovskite $\mathrm{CH} 3 \mathrm{NH} 3 \mathrm{PbBr} 3$ $\mathrm{xClx}$ films by modulating organic cation and chlorine concentrations," ACS Applied Materials and Interfaces, vol. 8, no. 20, pp. 12756-12763, 2016.

[18] C. A. Randall, A. S. Bhalla, T. R. Shrout, and L. E. Cross, "Classification and consequences of complex lead perovskite ferroelectrics with regard to B-site cation order," Journal of Materials Research, vol. 5, no. 4, pp. 829-834, 1990.

[19] K. Yao, X. Wang, F. Li, and L. Zhou, "Mixed perovskite based on methyl-ammonium and polymeric-ammonium for stable and reproducible solar cells," Chemical Communications, vol. 51, no. 84, pp. 15430-15433, 2015.

[20] S. Yang, Y. Wang, P. Liu, Y.-B. Cheng, H. J. Zhao, and H. G. Yang, "Functionalization of perovskite thin films with moisturetolerant molecules," Nature Energy, vol. 1, no. 2, article 15016, 2016.

[21] D. Shi, V. Adinolfi, R. Comin et al., "Low trap-state density and long carrier diffusion in organolead trihalide perovskite single crystals," Science, vol. 347, no. 6221, pp. 519-522, 2015.

[22] M. I. Saidaminov, A. L. Abdelhady, B. Murali et al., "Highquality bulk hybrid perovskite single crystals within minutes by inverse temperature crystallization," Nature Communications, vol. 6, article 7586, 2015.

[23] D. H. Cao, C. C. Stoumpos, O. K. Farha, J. T. Hupp, and M. G. Kanatzidis, "2D homologous perovskites as light-absorbing materials for solar cell applications," Journal of the American Chemical Society, vol. 137, no. 24, pp. 7843-7850, 2015.

[24] T. Baikie, Y. Fang, J. M. Kadro et al., "Synthesis and crystal chemistry of the hybrid perovskite $\left(\mathrm{CH}_{3} \mathrm{NH}_{3}\right) \mathrm{PbI}_{3}$ for solidstate sensitised solar cell applications," Journal of Materials Chemistry A, vol. 1, no. 18, pp. 5628-5641, 2013.

[25] Y. Yamada, T. Nakamura, M. Endo, A. Wakamiya, and Y. Kanemitsu, "Photocarrier recombination dynamics in perovskite $\mathrm{CH}_{3} \mathrm{NH}_{3} \mathrm{PbI}_{3}$ for solar cell applications," Journal of the American Chemical Society, vol. 136, no. 33, pp. 11610-11613, 2014.

[26] D. W. DeQuilettes, S. M. Vorpahl, S. D. Stranks et al., "Impact of microstructure on local carrier lifetime in perovskite solar cells," Science, vol. 348, no. 6235, pp. 683-686, 2015.

[27] N. K. Noel, A. Abate, S. D. Stranks et al., "Enhanced photoluminescence and solar cell performance via lewis base passivation of organic-inorganic lead halide perovskites," ACS Nano, vol. 8, no. 10 , pp. $9815-9821,2014$. 

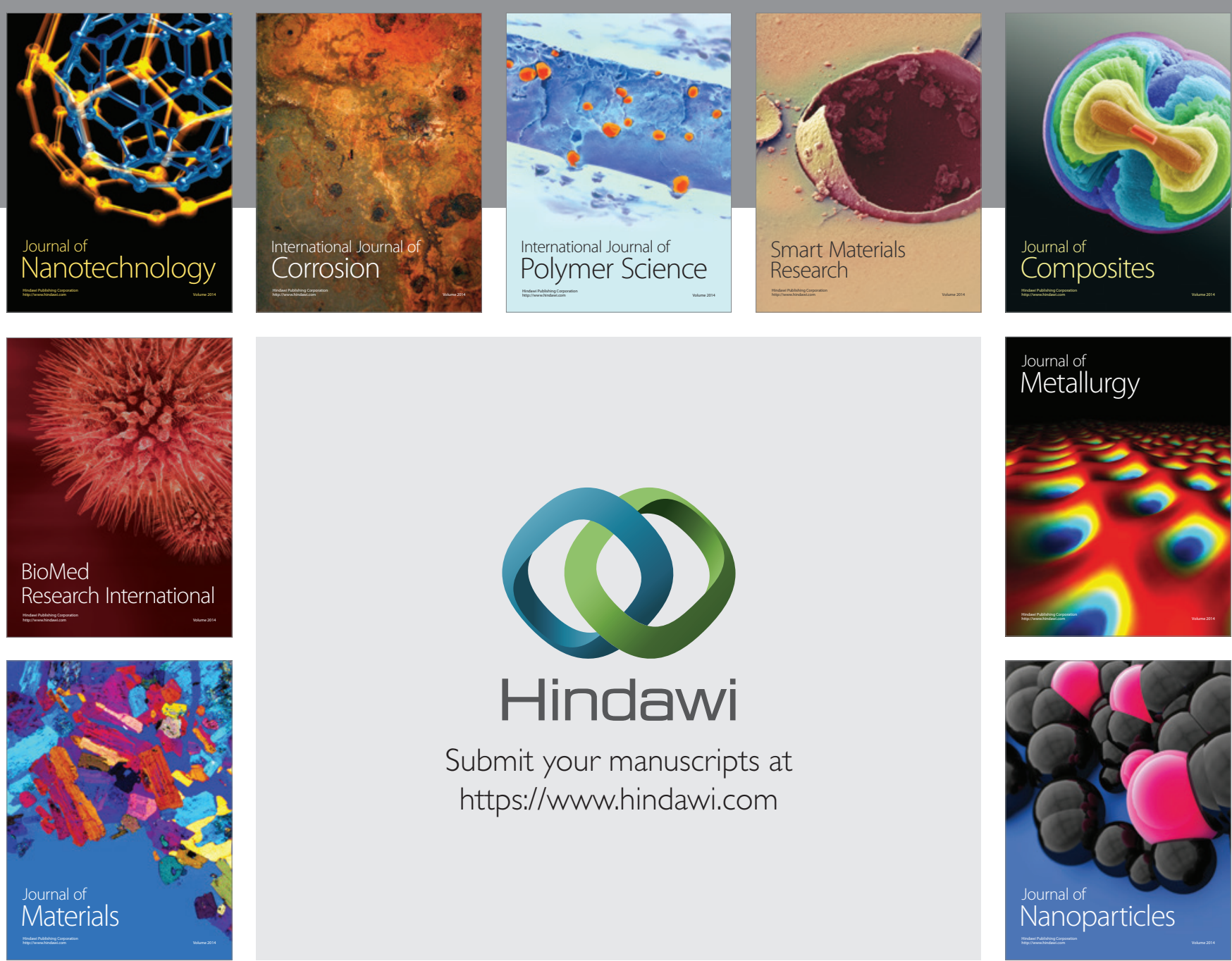

\section{Hindawi}

Submit your manuscripts at

https://www.hindawi.com

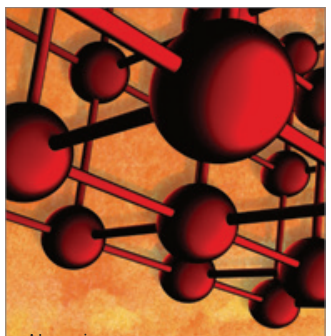

Materials Science and Engineering
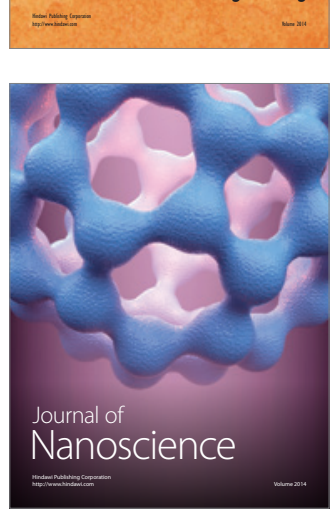
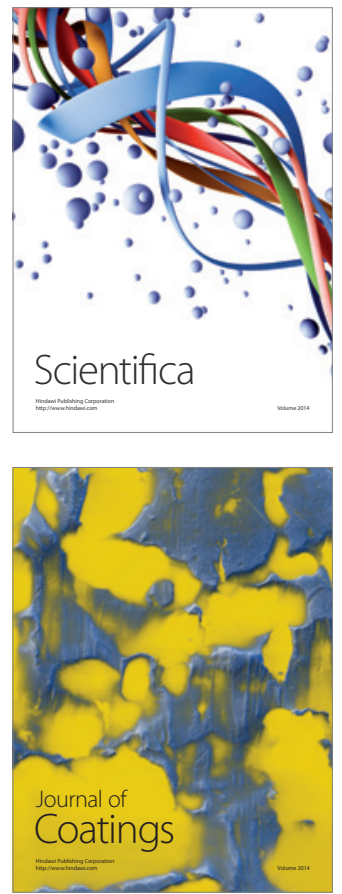
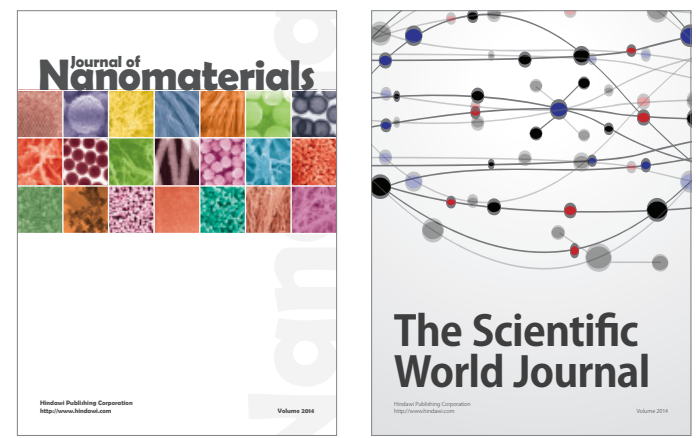

The Scientific World Journal
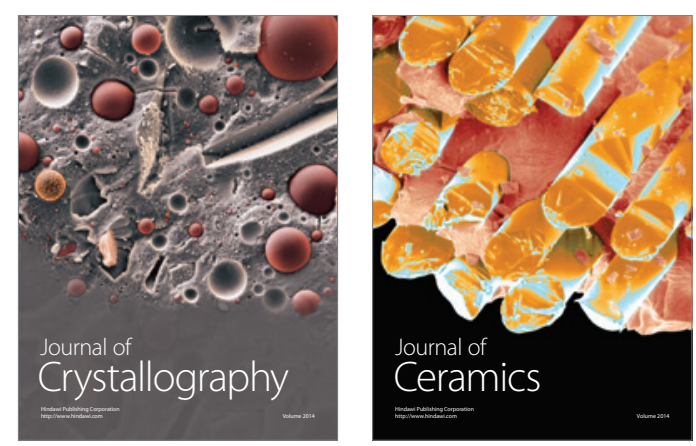
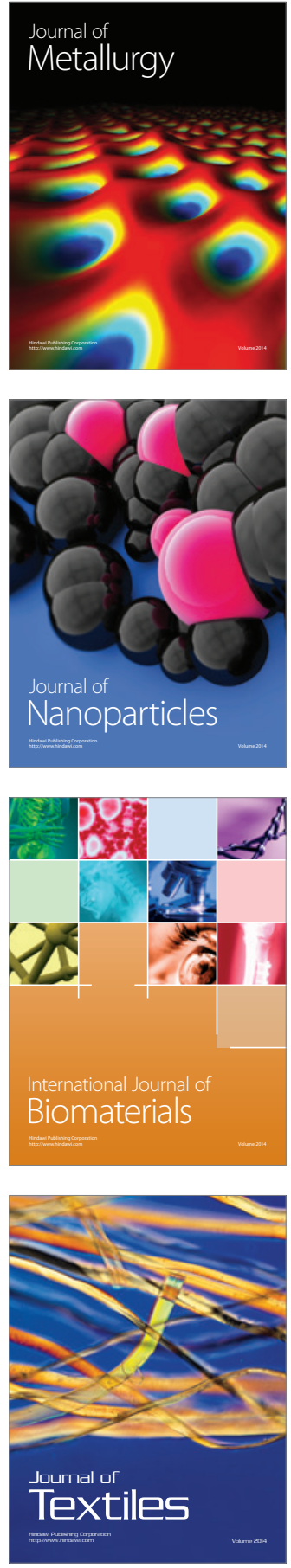